\title{
Carreiras militantes, redes de sociabilidade e formas de engajamento na luta contra AID S em Sergipe
}

Fernanda Rios Petrarca ${ }^{1}$

Maria Rita Ribeiro ${ }^{2}$

\section{Resumo}

Este artigo analisa a relação entre itinerários, formas de socialização e recursos individuais que marcam as carreiras dos militantes e as formas de engajamento na luta contra a AIDS em Sergipe. Trata-se de examinar, mais especificamente, os atores que estão reunidos em torno da problemática da AIDS em Sergipe, as conexões entre eles e o conjunto de laços sociais que mobilizam e que os conduz ao investimento militante. Partimos do princípio que as dinâmicas próprias das carreiras, associada à configuração do espaço, determinam, em certa medida, as formas de engajamento na luta contra a doença. As conclusões apontam para três padrões de carreira: primeiro as que estão marcadas pelas redes profissionais; segundo, aquelas que estão pautadas pelo pertencimento simultâneo a vários espaços de mobilização e, por fim, carreiras definidas pela contaminação com o vírus e redes decorrentes do tratamento com a doença.

Palavras-chave: carreiras individuais; recursos sociais; redes de sociabilidade; AIDS

\footnotetext{
${ }^{1}$ Doutora e pós-doutora em Sociologia, membro do Laboratório de Estudos do Poder e da Política da Universidade Federal de Sergipe e professora do Programa de PósGraduação em Sociologia da UFS. Pesquisador de produtividade em pesquisa do CNPq. E-mail: f.petrarca@uol.com.br

${ }^{2}$ Mestre em Sociologia pela PPGS/UFS. E-mail: mariarita.ciso@hotmail.com
} 


\section{Activist Careers, Social N etworks and involvement forms into the fight against AID S in Sergipe}

\section{Abstract}

This article examines the relationship between itineraries, forms of socialization, and individual resources as a basis for the involvement into the fight against AIDS in Sergipe. The aim is to examine the actors who are committed to the problem of AIDS, the connections between them and the set of social ties mobilizing and leading to the individual interest. The dynamics of careers and configuration of space determine the forms of participation in the fight against disease. The conclusion presents three career patterns: the first are those marked by professional networks; the second those which are guided by plural forms of participation and, finally, the careers defined by the contamination with the virus and the networks resulting from the treatment of the disease.

Keywords: careers; individual resources; social network; AIDS

Este artigo analisa a relação entre itinerários, formas de socialização e recursos individuais que marcam as carreiras dos militantes e as formas de engajamento na luta contra a AIDS. Trata-se de examinar, mais especificamente, os atores que estão reunidos em torno da problemática da AIDS em Sergipe, as conexões entre eles e o conjunto de laços sociais que mobilizam e que os conduz ao investimento militante. Partimos do princípio que as dinâmicas próprias das carreiras, associada à configuração do espaço, determinam, em certa medida, as formas de engajamento na luta contra a doença. Tal trabalho resulta, por um lado, de uma pesqui- 
sa mais ampla ${ }^{3}$ sobre a relação entre dinâmicas de atuação profissional e engajamento na defesa de causas sociais em Aracaju e, por outro, de uma dissertação de mestrado que teve como problemática central as carreiras daqueles que se engajaram na luta contra a doença na capital de Sergipe (RIBEIRO, 2014).

Uma das principais constatações da primeira pesquisa realizada é que a luta contra a AIDS se tornou um caso particular de articulação entre diferentes atributos e ativismo (PETRARCA, 2015). Nela podemos perceber um discurso bastante afiado no que diz respeito ao peso que exercem certas categorias profissionais, como os médicos, por exemplo, e diversos outros profissionais voltados para a área da saúde, assim como também o papel dos ativistas (dos movimentos homossexuais e LGBT) e dos soropositivos, o que torna uma causa peculiar na articulação entre usos do conhecimento e a mobilização. Assim, o exame da luta contra a AIDS é revelador da diversidade e pluralidade de saberes que podem ser mobilizados em seu favor. Cabe destacar que não estamos nos referindo exclusivamente ao conhecimento acadêmico, mas toda forma de saber que se produz, seja por uma relação direta com a doença, como no caso dos soropositivos, seja pela atuação em associações e militâncias anteriores ou pela própria prática médica.

Este tipo de pesquisa tem apontado como problema central o exame dos atores que estão prontos a investir no universo das causas, enfatizando as características sociais destes ativistas, os recursos que mobilizam para entrada nesta causa e consequente investimento, bem como as redes de relações das quais fazem parte. Entretanto uma análise dos atores precisa ainda incluir

\footnotetext{
${ }^{3}$ Esta pesquisa, denominada "Atuação Profissional e Engajamento Militante na Defesa de Causas Sociais no Estado de Sergipe" (PETRARCA, 2012), contou com o financiamento do CNPq por meio do edital Universal. Uma versão mais ampla sobre essa pesquisa pode ser encontrada em Petrarca 2013 e 2014 e um estudo sobre a luta contra a AIDS no Brasil pode ser obtida em Petrarca, 2015.
} 
um exame do contexto no qual estão inseridos e sua importância para produção de significados. Portanto, os tipos de atores que investem na causa da AIDS, assim como em outras causas sociais, não são definidos por características a priori, mas eles se constituem no curso das suas intervenções públicas e nos contextos de interação nos quais se engajam. Como bem já frisou Becker (2007), o entendimento das pré-condições não significa que um fato determinado acontecerá ou que um engajamento ocorrerá. Os atores agem com base nas situações que se apresentam e são elas que geram novas possibilidades de ação.

Nesse sentido, é uma sequência de eventos, situações e fatos que produzem um determinado resultado e criam possibilidades de ação, colocando em jogo as experiências acumuladas dos atores, permitindo o acionamento de determinadas competências e a mobilização das redes de relações. Estas situações (eventos, contextos, espaços de interação) permitem conectar os atores, tornando possível o acionamento das redes de relações e a mobilização de conhecimentos ${ }^{4}$.

Alguns trabalhos, lançados recentemente, têm se preocupado em destacar que a mobilização de um conjunto de propriedades sociais que um indivíduo carrega para entrada e investimento num espaço determinado de mobilização não é suficiente para explicar os processos de engajamento. É necessário ainda considerar o peso que exerce a mediação de conhecidos, parentes, amigos, que funcionam como intermediários fundamentais para garantir a entrada e a permanência no espaço de mobilização (SAWICKI \& SIMEANT, 2011; PASSY \& GIUNE, 2001; PASSY, 1998; OLIVEIRA, 2010). Além disso, é importante que se considere a posição que a pessoa ocupa nessa rede de relações, pois é dela que resultarão convites, indicações e até mesmo as motivações necessárias para a entrada na causa.

${ }^{4}$ Uma análise mais detalhada e aprofundada sobre a definição da situação pode ser encontrada em Fornel, M \& Quéré, L (1999). 
Nessa direção, a análise das redes nos permite compreender tanto a natureza do laço acionado no processo de mobilização quanto o impacto que possam ter nos níveis de engajamento. Por um lado, a natureza nos permite identificar a característica central dessa rede, se ela é formal- produto de vínculos com grupos e instituições- ou informal- produto de laços de amizade, familiares ou relações de trabalho. Por outro lado, ela possibilita o exame das oportunidades que as relações sociais oferecem para o processo de mobilização e que influenciam nas tomadas de decisão, podendo inclusive dar um sentido ao engajamento ou até mesmo reforçar identificações com a causa. Dessa forma, elas podem fazer o papel de mediação entre a causa e os aspirantes à militância.

Uma das maneiras de dar conta empiricamente desse conjunto de questões é através da análise biográfica. Por meio dela, é possível apreender os diferentes espaços sociais em que os ativistas estão inseridos e as múltiplas histórias de vida utilizadas para dar um sentido ao seu engajamento. Nesse sentido, o método biográfico e o enfoque nas carreiras, percursos, itinerários, permitem recorrer às biografias individuais ou coletivas, construídas segundo modalidades muito diferentes e presentes em pesquisas com objetivos e problemas diversos (PUDAL, 1994; PENEFF, 1994, BECKER, 2008). Nesta pesquisa, as narrativas biográficas e os relatos de vida tornaram-se as fontes principais dos dados, contando-se ainda com um conjunto de materiais divulgados na internet sobre a biografia dos ativistas. Os procedimentos metodológicos adotados consistiram, portanto, na realização de entrevistas biográficas.

Tomando como referência a noção de carreira, tal como adotada por Becker (2008) e Goffman (1996) e aperfeiçoada por outros autores, os relatos biográficos são reveladores, de um lado, de uma sequência de posições (sociais, familiares, escolares, profissionais, políticas) ocupadas pelo indivíduo ao longo da sua vida em espaços sociais e profissionais diversificados, dos laços que 
ele estabelece e das redes de relações que tece. De outro, eles expressam reconstruções do passado e revelam visões de si e do mundo, remetendo a diversos mundos sociais e formas identitárias (DUBAR \& TRIPIER, 1998a).

A análise das carreiras permite evitar aquilo que Péchu (2001) chama de "hipótese da desclassificação", a qual consiste em perceber o investimento em espaços militantes apenas como uma estratégia para evitar a desclassificação social e profissional. Mais do que isso, o exame das carreiras permite dar conta das relações entre lógicas situacionais ${ }^{5}$, lógicas subjetivas (as reconversões ideológicas) e um conjunto de redes de relações, competências e recursos acumulados ao longo do itinerário individual.

Nosso material empírico consistiu num conjunto de entrevistas com militantes que ocupam posições em diferentes espaços da luta contra a AIDS em Aracaju/Sergipe. 0 conjunto de problemas anteriormente citados nos permitiu organizar este texto em dois eixos fundamentais. 0 primeiro permite apreender a configuração do espaço da luta contra a Aids em Sergipe, uma vez que a forma como está organizado este espaço influencia as carreiras que nele se desenvolvem. Os perfis de carreiras se manifestam e ganham forma dentro de uma determinada configuração e se ajustam a redes de instituições. 0 segundo eixo se concentrará nos padrões de carreira observados a partir de um conjunto de relatos individuais. Tais padrões se diferenciam, fundamentalmente, pelas redes de relações que conduzem ao engajamento na causa da AIDS.

\footnotetext{
${ }^{5}$ Esse é o caso das configurações sociais, políticas e profissionais que estruturam a oferta militante, assim como das situações que se apresentam aos atores sociais e que podem ser estimuladores para ingressar na defesa de causas e permanecer engajados (Collovald, 2002).
} 


\section{Espaços de M obilização da Luta contra a AIDS em Sergipe}

Em Sergipe, os principais grupos a se mobilizarem em torno da AIDS foram, inicialmente, o movimento homossexual e, em seguida, determinados setores da medicina, sobretudo aqueles vinculados à saúde pública. A intensa atuação da mídia nacionalassociando a AIDS aos homossexuais e seus respectivos estilos de vida- tiveram um impacto decisivo nas formas de atuação do movimento homossexual, o qual se tornou um dos principais atores na construção da doença como um problema social. Ao responsabilizar os homossexuais à doença, a mídia contribuiu para organizar a experiência destes protagonistas que se viram no papel de reagir frente às acusações midiáticas (PETRARCA, 2015).

É a partir disso que explode em todo o país um conjunto de mobilizações protagonizadas pelos movimentos homossexuais. No caso de Sergipe, tais mobilizações antecedem o aparecimento do primeiro caso de AIDS no estado e se organizam em torno de palestras, discussões e atividades direcionadas para o público homossexual. Um dos precursores foi o grupo Dialogay, fundado em 1981, o qual se tornou um dos principais protagonistas na luta contra a epidemia, lançando campanhas, promovendo eventos e realizando atividades de conscientização e informação sobre a doença. Esse grupo teve um papel destacado no cenário nacional, conforme observa Galvão (2000), influenciando na forma como a doença seria tratada. Junto com o Grupo Gay da Bahia, ele conseguiu conjugar a luta contra o preconceito, e em busca da legitimidade dos homossexuais, com a construção de uma resposta à epidemia (GALVÃO, 2000; FACCHINI, 2005).

A atuação do movimento homossexual na resposta à epidemia foi tão forte que já no início dos anos 1980 tornava-se difícil distinguir a militância do movimento homossexual e o engajamento na luta contra a AIDS. A pauta do movimento foi afetada pro- 
fundamente pelo combate à AIDS e voltada à luta por políticas de saúde que prestassem serviços de assistência ao doente e que permitissem um tratamento adequado aos portadores do vírus. Se antes o movimento estava centrado em mobilizações contra o assassinato de homossexuais e em campanhas de conscientização e afirmação dos direitos dos homossexuais, agora suas pautas são completamente absorvidas pela problemática da AIDS (PETRARCA, 2015).

Podemos apontar essa como uma das primeiras fases de construção da AIDS como um problema social. Um dos principais desafios, nesse momento, era a luta contra o preconceito associado a uma falta de conhecimento sobre a doença. Isso fez com que as organizações, sobretudo aquelas voltadas à temática da homossexualidade, investissem em campanhas direcionadas aos aspectos sociais da AIDS, como falta de leito, dificuldade dos pacientes em conviver com a família, amigos e no espaço do trabalho, dentre outros dilemas pessoais e sociais. Em meio ao aparecimento de vários casos de AIDS no estado, é criado em 1987 o programa estadual DST/AIDS, tendo como seu principal representante um médico que já realizava um trabalho voltado às DSTs com prostitutas em bairros da periferia de Aracaju. Sua atuação anterior na medicina pública lhe permitiu a formação de uma rede de contatos com lideranças de movimentos sociais e prostitutas que foi essencial para seu investimento no programa estadual de combate à epidemia. De início, o programa consolidou uma frente de atuação a partir da relação com o movimento homossexual, centrando na distribuição de preservativos e na criação de leitos para os doentes.

Os anos 1990 são marcados pela diversidade de atores, com a fundação do Grupo de Apoio à Pessoas com AIDS (GAPA/SE), com a participação da Associação Sergipana de Prostitutas e com a fundação da UNIDAS, esta última voltada para os transexuais. 0 GAPA, fundado pelo médico coordenador do programa estadual, se destacou durante um período por ser uma associa- 
ção composta por médicos e advogados e por prestar assistência aos soropositivos. Porém, sua vida foi curta e, em seguida, a associação foi extinta.

Esse momento, que podemos demarcar como a segunda fase da luta contra a doença, é marcado pelo intenso investimento do Estado nos movimentos sociais e isto promoveu uma transformação no perfil dos militantes que precisavam se adequar às exigências para concorrer aos editais e obter os financiamentos públicos para seus projetos (PETRARCA, 2015). Dentre essas exigências, estava a capacidade técnica da instituição de contar com profissionais qualificados que podiam assumir os projetos. Isso incluiu médicos, assistentes sociais, psicólogos, advogados, dentre outros. Tal fato levou ao desaparecimento de muitas entidades que não conseguiram se adequar aos critérios e, ao mesmo tempo, permitiu o surgimento de outras. Entretanto, o aparecimento de muitas instituições motivado pelos editais e organizado em torno da prestação de serviços profissionalizados não constituiu garantia de permanência no espaço da mobilização. Dois exemplos podem ser citados. O primeiro é o caso do GAPA/ $\mathrm{SE}$, que por conflitos internos e denúncias de irregularidade no uso de verbas públicas não conseguiu se manter. 0 segundo é o caso do Dialogay, que teve um papel destacado na construção de espaços de luta contra a AIDS, mas que por denúncias de irregularidades e dispersão das lideranças, foi extinta no início dos anos 2000 .

A extinção desses grupos teve como consequência a reorganização dos atores no espaço da mobilização, o que conduziu a terceira fase de construção da doença. Essa fase está diretamente associada ao aparecimento das ONGs/AIDS. O Dialogay, por exemplo, participou da fundação do Fórum Permanente de Aids, em 2001, estando à frente desta instituição nos seus três primeiros anos de existência. Além disso, dois dos seus antigos dirigentes fundaram a Associação de Defesa Homossexual de Sergipe (ADHONS) e outro membro fundou a Rede Nacional de Pessoas 
Vivendo com AIDS. A fundação das organizações voltadas especificamente à temática da AIDS partiu, de um lado, de lideranças do movimento homossexual. E, de outro, de pessoas infectadas pelo vírus, que pela experiência com a doença se tornaram ativistas no combate à epidemia.

O espaço catalisador para o aparecimento das ONGS/AIDS em Sergipe é, fundamentalmente, o movimento homossexual e, posteriormente, o transexual. Tal predomínio do movimento GLBTT nas organizações voltadas especificamente à questão da AIDS se manifesta na direção das entidades. Das cinco entidades que estiveram à frente do Fórum nesses 12 anos de existência, três são voltadas à militância GLBTT. Atualmente, está à frente a Astra, entidade voltada à defesa dos transexuais, dos direitos humanos e cidadania GLBTT.

Uma das explicações possíveis para tal configuração está relacionada ao desenvolvimento e expansão do movimento homossexual em Sergipe. Frequentemente apresentado pela literatura (MELO, 2011; COSTA, 2012) como um dos mais antigos do país, sua emergência data o início da década de 1980. Antes disso, contudo, já é possível identificar, no curso da década de 1970, as primeiras formações e agrupamentos. 0 aparecimento da AIDS deu novo impulso ao movimento, contribuindo para sua expansão e consolidação. Enquanto a década de 1980 voltava-se para o preconceito e crime contra homossexuais, as décadas seguintes concentraram a atividade em torno da temática da AIDS. Podemos citar como exemplo as campanhas de valorização dos homossexuais e em defesa de sua autoestima, como a campanha liderada pelo grupo Dialogay, cujo slogan: "É Legal ser Homossexual". Além de panfletos e folhetos informativos alertando para crimes contra os homossexuais. Tais panfletos visavam promover denúncias de crime e dicas de proteção para os homossexuais, como o "Manual de sobrevivência: dicas para evitar a violência anti-gay- Gay vivo não dorme com o inimigo" divulgado pelo Dialogay. Os anos 1990, sobretudo, foram os anos de combate 
à epidemia e de intensa inserção das organizações nas políticas de combate à AIDS no Estado. Iniciativas como a organização do I Seminário sobre DSTs/Aids em Sergipe, em 1987, e a criação do "Comitê de Apoio às Vítimas da AIDS" -ambas impulsionadas pelo grupo Dialogay- ilustram essa questão.

Atualmente, a luta contra AIDS se consolida em Sergipe institucionalmente nos seguintes espaços: esfera estatal com programas estaduais e municipais, esfera dos movimentos sociais e espaços organizados, sobretudo no movimento GLBTT e nos grupos voltados à temática da AIDS - como o Fórum de ONGs AIDS, Rede de Mulheres Cidadãs Positivas (RMP+), Rede de Pessoas Vivendo com AIDS (RNP+) e Rede de Jovens Vivendo com AIDS (RNJ+). A RNP+ foi fundada por uma liderança do movimento homossexual e a RMP+ e a RNJ+ surgiram de dentro da RNP+, constituindo uma setorialização da mesma. Esse movimento também ocorreu em nível nacional.

Cabe destacar que do conjunto de 33 entidades que compõem a relação de ONGs do programa estadual de luta contra a AIDS, 12 são vinculadas ao movimento GLBTT e 3 destinadas especificamente à questão da AIDS. As demais se dividem em temas diversos, tais como: a causa da saúde, defesa das mulheres e direitos humanos. Vale ressaltar que desta relação de 33, apenas 11 são efetivamente ativas, com participação destacada nas campanhas. E dessas 11, três são de entidades voltadas à temática da AIDS e 5 são GLBTT.

Por um lado, a fragmentação sofrida pelo movimento homossexual- que também pode ser observada no cenário nacional- e sua dispersão em outros grupos (como mulheres e negros homossexuais, ou transsexuais), que não se sentiam representados pelas organizações homossexuais, levou muitas organizações a divisão e consequente extinção. No que diz respeito ao espaço nacional, a dispersão entre os grupos se tornou tão intensa que dos 22 grupos atuantes no país em 1980, restaram quatro em 1985 e três em 1986 (FIGARI, 2007). 
Por outro lado, a política nacional de AIDS criava as condições para que grupos específicos voltados à causa da AIDS compusessem os projetos na luta contra a doença. 0 enfraquecimento das organizações voltadas à causa homossexual e o aparecimento de grupos que se fortaleceram a partir do vínculo com os projetos estatais, nacionais e políticas de AIDS, marcam esse momento do ativismo. Acordos entre os governos e órgãos internacionais para fins de financiamento estimularam a criação de ONGs/AIDS em todo o país. O período que se estende de 1992 até 1997 é apresentado como um momento de intenso envolvimento dos programas estaduais e federais com as organizações não governamentais, o que estimulou a criação de muitas delas. Em 1992, existiam no país 82 ONGs/AIDS e, em 1994, mais de 250 são constituídas no país (FIGARI, 2007).

A breve descrição da configuração desse espaço de luta serve para demonstrar como ele cria as condições para realização do engajamento nessa causa, afetando, portanto, as carreiras que neste espaço se desenvolvem. Assim, cada fase de construção da doença como um problema público, oferece aos atores locais possibilidades de atuação, estimulando uma determinada forma de mobilização. Como veremos no tópico seguinte deste texto, as carreiras não ocorrem no vazio social, mas elas estão diretamente associadas à forma de organização do espaço que, por sua vez, estrutura as oportunidades e funciona como um "espa-

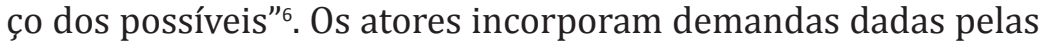
redes institucionais e organizam suas carreiras com base nisto.

\footnotetext{
${ }^{6}$ Essa expressão é utilizada por Bourdieu (1996) para designar um espaço de posições possíveis de serem ocupadas pelos agentes. Estamos usando-a aqui para compreender de que forma o estado em que se encontra o espaço social oferece as condições para o desenvolvimento das disposições, das aptidões, do acionamento das redes de relações e das possibilidades de carreira.
} 


\section{As Redes que Conduzem ao Engajamento: Formas de Ingresso e Carreiras M ilitantes}

Para melhor apresentar os dados dos percursos individuais, organizamos o material biográfico em três padrões e selecionamos os casos que mais ilustram as formas de investimento na causa. Primeiro, estão aqueles cujas carreiras profissionais foram atravessadas pelo aparecimento da AIDS, cujo caso representativo é o do atual coordenador do Programa Estadual de AIDS. A questão central nesse caso são as redes profissionais que conduzem ao engajamento. Segundo, estão aqueles para os quais a AIDS representa uma das causas com as quais se envolveram ao longo dos seus itinerários e cujas carreiras militantes são marcadas pelo pertencimento simultâneo a vários espaços de mobilização. Portanto, a característica central aqui são as múltiplas redes (formais e informais) derivadas do investimento em várias causas e movimentos sociais. E, por fim, aquelas carreiras cuja marca central é ter sido contaminado pelo vírus da AIDS. Esses três padrões de carreira envolvem dinâmicas próprias, dilemas específicos, mas em todos eles podemos perceber o peso das redes de relações não só para fazê-los investir na causa, mas para, sobretudo, fazê-los permanecer.

\section{"D outor Camisinha": redes profissionais, paixão e luta contra AIDS}

O caso que utilizaremos aqui para ilustrar o papel das redes profissionais no envolvimento e combate à AIDS é a do coordenador do Programa Estadual de Combate à AIDS e DST’s de Sergipe. Há 25 anos atuando como coordenador do referido programa, desde sua criação em 1987, o médico entrevistado representa uma carreira profissional estruturada, inicialmente, em torno das doenças sexualmente transmissíveis e, posteriormente, em torno da AIDS. Sua atuação como médico de saúde pública e sua experiência profissional com as doenças de origem sexual lhe renderam inúmeros apelidos: "Dr. das Putas”, “Dr. dos Bichas” e o mais conhecido deles: "Dr. Camisinha”, 
conforme ele mesmo explicita. Contemplado com diversos prêmios em nível nacional, se destacou na mídia pelas suas ideias criativas no combate à epidemia. A primeira a se destacar foi o "Bloco da Prevenção", criado em 1994 durante o evento do Pré-Caju7 e que se constituiu como uma ideia "bem-humorada" de prevenção. Tratava-se de um bloco que acompanhou alguns trios e que distribuía panfletos sobre DST's e AIDS, além de divulgar o uso de preservativo. 0 bloco chegou a desfilar com 5.000 pessoas. A segunda foi o Camisildo: uma Kombi sob a forma de uma camisinha que puxou o "Bloco da Prevenção" durante o Pré-Caju. Essa iniciativa foi premiada com o 4⿳亠丷a Edição do Prêmio AIDS de Responsabilidade Social Saúde. 0 Camisildo circula durante eventos populares e funciona divulgando informações sobre doenças sexualmente transmissíveis e AIDS e distribuindo preservativos. A terceira, e a mais recente delas, é um ônibus itinerante que realiza testes de DST's e AIDS de forma gratuita.

Natural de Aracaju e de origem social "humilde", como declarou em entrevista, enfrentou todas as dificuldades de um aluno cujos pais carecem de recursos econômicos. Com seus pais e irmãos -mãe costureira e pai caminhoneiro- passou a infância "de menino pobre" no bairro Santo Antônio ${ }^{8}$. Sua formação escolar, desde os primeiros anos de estudo até o curso universitário, ocorreu toda em escola pública. Contudo, é importante frisar que as escolas púbicas, no contexto de sua formação, eram também frequentadas por grupos sociais com capital econômico elevado. Esse é o caso da escola Atheneu Sergipense ${ }^{9}$, um importante

\footnotetext{
${ }^{7}$ Evento que ocorre em Aracaju no mês de janeiro e que antecipa as comemorações do carnaval na cidade.

${ }^{8} \mathrm{O}$ bairro, que surgiu no topo de uma colina, é um dos mais antigos da cidade. No inicio do século XX passou a ser ocupado por grandes casarões coloniais que se situavam no alto do morro. Contudo, com a expansão da cidade na década de 1960, o bairro apresentou sinais de estagnação econômica e passou a ser ocupado por grupos de baixa renda. ${ }^{9}$ Essa escola teve um papel importante na formação de muitos médicos, escritores, políticos e advogados nas décadas de 1940 a 1980. Considerada uma das mais importantes escolas do estado nesse período, teve um papel destacado na formação de grupos dirigentes em Sergipe. São exemplos de dirigentes que se formaram nela: Graccho Cardoso (governador do Estado) e José Calazans (escritor e intelectual).
} 
colégio estadual da cidade que se tornou palco de formação de políticos e de lideranças estaduais. Assim como ele, quase todos os seus colegas ingressaram na Universidade Federal de Sergipe, sobretudo no curso de medicina. A experiência no colégio Atheneu teve um peso significativo na sua trajetória escolar, uma vez que nesta escola conheceu professores que o incentivaram a continuar os estudos e colegas que mais tarde se tornariam importantes aliados. É exemplo disso a fundação, em 1974, do curso pré-vestibular Visão, do qual participou juntamente com outros colegas da UFS e também do Atheneu. Nesse curso ministrava a disciplina de biologia e com o salário conseguia manter as despesas que a formação em medicina exigia. Dessa forma, o ingresso e investimento no colégio Atheneu se constituiu como um passo importante da sua carreira, visto que dentro desta escola pôde estabelecer laços sociais que seriam importantes no seu percurso social e profissional.

Ingressou no curso de medicina em 1974 e concluiu em 1981, com um ano de atraso, pois precisou trancar a faculdade por conta dos gastos onerosos. A intensa atividade no curso Visão, onde ministrava disciplinas no turno da manhã, associada aos custos do curso de medicina, o levou a trancar o semestre. Formado enfrentou as dificuldades de inserção no mercado de trabalho e pôde perceber que até mesmo para médicos "empregos não caem do céu". Os dois primeiros anos de formado foram dedicados ao ensino de biologia.

Um período muito difícil, momento de angústia. Queria trabalhar, mas não tinha oportunidade. Sendo uma pessoa calada, sem saber pedir, continuei na minha maneira de ser.

Esse relato permite compreender, primeiro, que o acesso ao mundo dos empregos depende de um conjunto de laços sociais estabelecidos e mantidos e que até mesmo para os ofícios mais institucionalizados, como a medicina, eles são imprescindíveis. São eles, portanto, que conduzem a inserção no mercado de tra- 
balho e sua respectiva ascensão. Segundo, é preciso desenvolver habilidades para conquistar e acessar esses laços. A capacidade para firmar relações e expandi-las depende de um intenso investimento pessoal.

Na tentativa de dar prosseguimento a sua carreira médica, com o auxílio econômico do pai, montou um consultório junto com outro colega. Nesse mesmo momento, ingressou no Estado como médico clínico, concentrando sua atuação em um Posto de Saúde situado no bairro Santos Dumont ${ }^{10}$. Nessa época, o médico para atuar no serviço público fazia uma espécie de inscrição, escolhia o bairro e depois era chamado. Já na sua inscrição fez a opção para atuar em qualquer bairro da cidade, "de preferência o pior", conforme relatou na entrevista, o que lhe garantiu o emprego logo em seguida, pois a vasta maioria dos seus colegas não tinha interesse neste tipo de trabalho. No referido posto de saúde começou o contato com as famílias que viviam na comunidade, por meio de campanhas -como as de vacinação- e do tratamento de doenças que exigiam um maior envolvimento do profissional de saúde e um conhecimento sobre a vida do paciente. Essa experiência lhe permitiu o desenvolvimento de um conjunto de habilidades que mais tarde lhe foram úteis, tais como: capacidade de negociar com a comunidade, estreitar laços, estabelecer vínculos, fazer contatos com lideranças locais, atuar coletivamente e comandar um grupo profissional.

Ao mesmo tempo, seu consultório crescia rapidamente, aumentando cada vez mais o número de pacientes. Contudo, a possibilidade de associar medicina pública com medicina privada começou a ser prejudicada a partir do momento em que se intensificava o envolvimento com o tratamento de doenças sexualmente transmissíveis. Seus investimentos nessa área tiveram início durante uma campanha de vacinação da poliomielite em

\footnotetext{
${ }^{10}$ Considerado um dos bairros mais pobres da cidade, com elevados índices de violência e criminalidade, está situado na periferia de Aracaju.
} 
que resolveu percorrer o bairro para melhor divulgar a necessidade da vacina. A vacinação fora do posto não era comum nessa época e sua iniciativa gerou simpatia por parte dos moradores da comunidade. Nessa visita à comunidade, se deparou com inúmeras casas de prostituição, o que o estimulou a realizar também diversas campanhas de prevenção e tratamento da sífilis e de outras doenças sexualmente transmissíveis recorrentes.

Eu descobri que o Santos Dumont era um bairro que tinha muitos prostíbulos. Fiz um mapa do bairro e comecei a visitar um por um, atendendo às prostitutas, solicitando exames de sífilis (Santos, 2004).

Essa realidade lhe aproximou das prostitutas da comunidade que passaram a frequentar o posto para ter acesso aos preservativos que evitariam as doenças sexuais. A experiência como médico clínico naquele posto de saúde e o investimento em doenças sexualmente transmissíveis, sobretudo voltadas a um público determinado- as prostitutas- redirecionaram seus investimentos profissionais, contribuindo para fortalecer o seu comprometimento e engajamento na medicina e criando um espaço de atuação profissional: a medicina pública. Além disso, esse investimento não lhe permitiu associar medicina privada, em consultórios, com medicina pública. 0 investimento em DST's e, em especial, a AIDS, deixou uma marca difícil de ser ultrapassada.

Perdi o consultório. Tentei por duas vezes. Na primeira vez, tentei um consultório no edifício Paulo Figueiredo, mas o que recebia não dava para pagar o aluguel. Muita gente não ia porque dizia assim: para o doutor Almir só vai quem tem AIDS. Muita gente que não me conhecia, gostava, voltava e quando descobria a verdade, chegava a me perguntar: o senhor é aquele médico da AIDS? (Santos, 2004).

Quando os primeiros casos de AIDS começaram a aparecer em Sergipe, ele já era conhecido em Aracaju como um médico que 
tratava doenças sexualmente transmissíveis na periferia, sobretudo sífilis. Como não havia médicos que se disponibilizassem a tratar tais pacientes- uma vez que o medo do contágio era grande- eles lhes eram enviados. A partir desse momento passou a se envolver intensamente com o tema, participando de eventos, fazendo cursos, divulgando informações sobre formas de contágio da AIDS e investindo na relação com os movimentos sociais, sobretudo o movimento homossexual, bastante ativo em Aracaju, e a Associação das Prostitutas. É por meio da participação nesses eventos que ocorre a primeira aproximação com o movimento homossexual, posteriormente fortalecida e intensificada. Esses dois grupos se constituíram, no início da epidemia, como os principais grupos de risco e alvos de inúmeras formas de discriminação e preconceito. Portanto, se tornam seus importantes aliados. Nesse momento, dois personagens se tornam essenciais na sua relação com esses dois grupos: Wellington Andrade, do Dialogay, e Candeláriaa ${ }^{11}$, que na época representava as prostitutas. É com esses dois ativistas que, mais tarde, fundará o Grupo de Apoio aos Portadores de AIDS (GAPA/SE).

Com o avanço da doença e a criação do Programa Federal de Luta contra a AIDS, os estados da federação criaram também os seus programas estaduais. De início, seu nome foi cogitado para organizar e conduzir o Programa Estadual na Luta contra AIDS. Podemos perceber, portanto, que as redes de relações decorrentes da sua atuação profissional na luta contra as DST's como médico de saúde pública sustentam sua entrada, e posterior permanência, na causa da AIDS.

Inicialmente seus contatos estavam centrados nos grupos e movimentos sociais na tentativa de intensificar as campanhas de saúde e permitir uma maior aproximação com determinados setores. Posteriormente, com a atuação no Programa Estadual, fortalece seus vínculos com políticos (desde governadores à pri-

${ }^{11}$ Na década de 1990 fundou a Associação Sergipana de Prostitutas (ASP). 
meira dama) e com as famílias dos doentes. Com os políticos, a citação abaixo, extraída da sua entrevista, releva a natureza dos vínculos e a forma como foram sendo estabelecidos:

Com os políticos eu respeito a todos, eu não quero nem saber qual é o partido, eu atuo, eu sempre procurei ter uma posição assim. Tenho os meus votos, mas no meu trabalho não tenho tendência, embora já fui muitas vezes confundido. E continuo na luta. Cada governo é um trabalho de convencimento. E quando coloca secretário de fora de Sergipe que não conhece até a minha história. (...). Eu sempre fui bem com as primeiras damas. Eu sempre militei todas. (...)

Sua relação com os políticos- ao longo de 28 anos num cargo que é de indicação do governo do estado- requer cautela e ao mesmo tempo habilidade. É assim que as primeiras damas se tornaram importantes aliadas. Questionado sobre como essa relação é estabelecida ele revela:

É o seguinte: você é a primeira dama, eu chego para você e digo: seu município tem tantos casos de AIDS, vou explicar o que é a AIDS. Se você não ajudar é pior. Aí eu vou mexendo... Eu já pedi a esposa do DEDA (...), eu disse: olha você está me devendo (...). Eu procuro, quebro hierarquia, furo fila. Eu adoro furar fila.

A estreita relação estabelecida, ao longo de duas décadas, com o universo da política, e em especial com as primeiras damas, garantiu a Sergipe o acesso aos primeiros medicamentos de controle da doença. O HAART, como foi chamado o coquetel da AIDS, chegou ao estado por meio da esposa do então governador Albano Franco, Leonor Franco, que na ocasião era presidente do Conselho Nacional do Serviço Social e da Indústria (SESI), cargo que exerceu de 1994 até 2003. Leonor, que chegou a ser presidenta da Legião Brasileira de Ação Social (LBA) e ministra da Ação Social do governo Ita- 
mar Franco, entre 1993 e 1994, fez a primeira compra do HAART do Brasil por meio do SESI.

Assim, a gestão dos vínculos políticos se torna fundamental para compreensão do seu engajamento na luta contra a AIDS, uma vez que contribui para o aprofundamento e intensidade da sua militância na causa. 0 investimento nessas relações garante o acesso à política, o que vai desde conseguir leitos, medicamentos, internamento para pacientes e assistência às famílias, até a manutenção de sua função no cargo. Além disso, tais investimentos contribuem também para exercitar e desenvolver o que se costuma denominar como "artes da política"12. As habilidades para a política, sobretudo estas que um cargo como o de coordenador estadual de uma política pública exige, são, portanto, desenvolvidas no decorrer de longos anos e são apreendidas por um processo de intenso investimento pessoal.

Tais investimentos como médico clínico e posteriormente como gestor de política de AIDS, lhe permitiram, por um lado, adquirir conhecimentos sobre saúde pública, por outro lado, uma habilidade para negociar com grupos e com a própria comunidade. Segundo afirma, seu envolvimento ultrapassa o saber médico e envolve desde o contato com lideranças comunitárias, até a busca pelo atendimento das necessidades mais amplas dos pacientes (conseguir leitos, cesta básica, resolver conflitos familiares, etc.). Além disso, seu comprometimento com a medicina se intensifica, contribuindo para dar um sentido à sua atuação profissional.

Eu tenho uma vivência que é diferente de um médico normal. Eu sou um médico anormal. Tem coisas hilariantes e tem coisas tristes. (...) 0 lado financeiro é uma desgraça. Mas eu me vejo como um médico que amo o que eu faço. Eu abracei esta causa e amo o que faço. (...). Eu adoro a saúde

${ }^{12}$ Essa expressão é utilizada por Canedo (2003). 
pública. Eu acho que eu sou mais importante com a massa, porque é mais fácil você ter um médico no consultório do que no posto de saúde.

Eu gosto de ajudar os outros.

Pode-se dizer que a associação entre o aparecimento dos primeiros casos de AIDS em Sergipe, a necessidade de o governo criar uma política estadual a partir de um programa e o investimento que esse médico já fazia com doenças sexualmente transmissíveis se tornaram eventos cruciais e que marcaram não só sua entrada na luta contra AIDS, como também seu comprometimento com a medicina. Procuramos destacar, nesse caso, que o investimento profissional na defesa de causas, em especial a luta contra a AIDS, não consiste apenas em uma estratégia para acumular relações suficientes capazes de serem reconvertidas em recursos políticos, permitindo uma ascensão no universo profissional. Mas tal investimento se caracteriza, principalmente, por oferecer um novo sentido ao investimento profissional e por caracterizar uma reconversão ideológica. 0 engajamento na luta contra a AIDS é, portanto, o encontro entre condições objetivas de realização -tais como a configuração do espaço, as redes de relações, os contatos estabelecidos, o investimento na saúde pública e a concentração em doenças sexualmente transmissíveis- e as lógicas subjetivas (percepção da atuação profissional, princípios de identificação com a causa). 0 principal desafio neste tipo de pesquisa é associar uma análise dos recursos sociais e das formas de socialização que caracterizam a entrada e permanência na defesa de causas com um exame das lógicas subjetivas que marcam tais ingressos e engajamento.

\section{A Pluralidade das Redes: o multi-engajamento e seus diversos caminhos}

A segunda modalidade definida é caracterizada pelo engajamento em vários espaços de atuação, causas e movimentos sociais. 0 caso que serve de suporte para essa modalidade é 
a de uma liderança que ocupou o cargo de coordenador do programa municipal de combate à AIDS em Aracaju. Formado em história e especialista em Gestão de Saúde Coletiva, esse ativista se caracteriza pela atuação em diversos movimentos sociais. Sua entrada nos espaços de mobilização tem início na adolescência, ainda no final da década de 1980, através de passeatas, caminhadas e manifestos. Em seguida, ingressou no Grêmio estudantil, compondo parte da União dos Estudantes Secundaristas e da União da Juventude Socialista e filiando-se ao PC do B.

No início dos anos 1990, começou a participar do Grupo Dialogay, no qual atuou durante um curto período, uma vez que precisou se afastar da cidade de Aracaju para trabalhar no interior do Estado. No seu retorno à Capital investiu em vários cursos no mundo das artes, como dança e teatro, atuando assim em diversas frentes. Segundo ele: "tinha vontade de ser artista". E foi assim que conheceu a Sociedade Afrosergipana de Estudos e Cidadania $(\mathrm{SACI})^{13}$, através da qual teve a oportunidade de se aproximar do movimento negro e das religiões de matrizes africanas.

O que se percebe é que o envolvimento com os movimentos GLBTT e negro foi fundamental na constituição de um "eu militante", pois foi assim que ele assumiu a sua homossexualidade e a sua cor, rompendo maneiras de ser e pensar associadas a experiências anteriores. Com a intensa militância nessas organizações, pode ter acesso a um conjunto de atividades, eventos, debates que conduziam a uma promoção da identificação racial e homossexual. Dessa forma, a participação no universo da defesa de causas e a inserção em redes de ativis-

\footnotetext{
${ }^{13}$ Vale ressaltar que a ONG SACI representava no cenário do movimento negro sergipano umas das mais importantes associações, concentrando no final dos anos 1990 um orçamento anual de $\mathrm{R} \$ 200.000,00$. Além disso, essa entidade, que desfrutava de importante visibilidade pública e acionava um conjunto de equipes técnicas, foi uma das principais articuladoras do Fórum de Entidades Negras do Estado de Sergipe.
} 
tas tiveram impacto significativo nas formas de percepção de si e no engajamento moral $^{14}$.

Em 1995 eu participei de algumas oficinas de um projeto chamado Oué, que significava comunidade na língua ioruba que era da SACI (Sociedade afrosergipana de estudos e cidadania) e, a partir daí, criei vínculo com o movimento negro, comecei a questionar o racismo, comecei a me identificar enquanto homem negro e a querer contribuir com essa luta, fui conhecer o candomblé, a umbanda, as religiões de matrizes africanas né! Que até então eu tinha muito preconceito e, foi o movimento negro que me resgatou essa identidade ancestral, eu comecei a me aproximar. (Entrevista concedida dia 12/01/2011).

Através da SACI e da socialização na cultura afro, promovida por esta entidad $\mathrm{e}^{15}$, esse ativista passa a se reconhecer como homem negro e a se identificar com a causa racial, direcionando, portanto, suas habilidades de liderança -apreendidas nos espaços anteriores (movimento estudantil, partidos políticos)- para as lutas pela igualdade racial. Além disso, esse tipo de investimento lhe permitiu construir um sentido para sua ação militante, intensificando seu engajamento nessa causa. Mas sua atuação na SACI lhe permitiu também um contato maior com outros movimentos sociais, o que contribuiu para acumular funções em outras entidades e promover, ao mesmo tempo, engajamento político partidário, ocupando inclusive cargos em todos os seguimentos:

Em 1999 eu me reaproximei do grupo Dialogay de Sergipe, fui convidado pra fazer parte da diretoria e entrei pra diretoria e, logo em seguida, eu fui convidado pra ser vice-presidente em 1999, naquele momento aquilo foi muito impor-

${ }^{14} \mathrm{O}$ engajamento moral é entendido aqui como um engajamento de si, como expressa Collovald (2002), uma reconversão identitária. Em outras palavras, trata-se da forma como as experiências no universo militante promovem uma mudança nas visões de si mesmo e do mundo.

${ }^{15}$ Dentre as atividades promovidas pela entidade estavam cursos de dança, teatro, arte em geral, direcionadas para a questão afro. 
tante porque era o segundo grupo mais antigo do Brasil, de homossexuais, tinha todo um respaldo em cima do nome do grupo Dialogay de Sergipe, quando a gente ia pros eventos nacionais que discutia a questão LGBT, assim como também as ações relacionadas à saúde, principalmente a prevenção de DST e AIDS, ai em 2002 o Dialogay foi extinto e nós fundamos o ADHONS que é a Associação de Defesa dos Homossexuais de Sergipe. (Entrevista concedida dia 12/01/2011).

Com a inserção no Dialogay, a discussão sobre a questão da AIDS se intensifica, pois, o grupo, como já foi dito, encabeçou as campanhas no combate à doença no Estado. Ou seja, o cargo ocupado na diretoria do Dialogay acarretava em um duplo engajamento: o primeiro no combate à homofobia e o segundo na luta contra a AIDS. Este último lhe rendeu um cargo na secretaria de saúde como coordenador do programa municipal de DST/AIDS da prefeitura de Aracaju. 0 primeiro vínculo com políticas de AIDS surgiu como mediador do programa com os movimentos sociais, em função da sua inserção em organizações e entidades. Com a saída do coordenador, ele acabou sendo o nome escolhido para ocupar o cargo de coordenador.

Eu cheguei aqui graças a esse histórico de atuação dentro da luta contra a epidemia, dentro da luta em defesa dos direitos humanos, porque o trabalho com DST/AIDS também tá muito relacionado com os direitos humanos, porque o preconceito ainda é muito forte, então você trabalha muito combatendo o preconceito (op. cit.).

Além disso, seu investimento na luta contra a AIDS, por meio da participação no Dialogay, contribuiu significativamente para seus investimentos profissionais, uma vez que é para intensificar e fortalecer o engajamento nesta causa que ele fez um curso de especialização em Gestão de Saúde Coletiva. Portanto, suas carreiras - profissional e militante - aparecem como indissociáveis e são construídas de forma entrelaçadas, garantindo o acesso a um conjunto de cargos e funções que contribuem para intensi- 
ficar seu papel profissional e seu investimento no universo das causas. Concomitante à AIDS, outros investimentos e cargos já haviam sido feitos e conquistados. Um deles foi o cargo ocupado na Fundação Municipal de Cultura, Turismo e Esportes (FUNCAJU), como chefe da seção de etnias, um trabalho que está vinculado ao engajamento no movimento negro. Todo o saber que foi sendo adquirido dentro da militância foi fundamental para a ocupação dos cargos na FUNCAJU e na Secretaria Municipal de Saúde.

Essa relação dos movimentos sociais com o Estado é muito presente no combate à AIDS, como vimos no tópico anterior, tornando-a uma marca da luta contra a doença no Brasil e configurando um espaço de possibilidades. 0 que se pode perceber é que o saber apreendido dentro dos movimentos sociais é fundamental para fazer esta ligação entre Estado, profissionais e sociedade civil.

\footnotetext{
Então essa relação dos programas tanto nacional, como estaduais, como municipais é muito forte com os movimentos sociais, nós sempre dizemos que nós precisamos deles e que eles precisam de nós, no meu caso que eu fico meio lá, meio cá, eu preciso de todo mundo e todo mundo precisa de mim, porque eu sou meio movimento, meio gestor, mas assim a gente reconhece a importância desses atores, até porque o profissional de saúde ele tem a sua formação acadêmica e muitas vezes não vê os conteúdos necessários pra sua atuação, pra lidar com tantas diversidades.
}

É importante perceber o caminho percorrido por essa liderança até a sua inserção no combate à AIDS. Com essa diversidade de movimentos e todo um saber acumulado em mais de 25 anos em movimentos sociais, o entrevistado foi de grande importância para um papel de mediação entre a secretaria de saúde e os movimentos que combatem à AIDS. 0 que se pode perceber é que existe um conjunto de saberes e investimentos, que são ao mesmo tempo profissionais e militantes, que foram agregados 
ao combate à doença e que são fundamentais para compreender o acesso ao cargo que atualmente ocupa. De um lado, são as redes de relações construídas no âmbito de múltiplos investimentos militantes que o levam a causa da AIDS, de outro, tais investimentos foram fundamentais para redirecionar não só seu engajamento como também sua atuação profissional.

\section{D e V ítima a Ativista: entre a militância e a soropositividade.}

Esta última modalidade de engajamento na luta contra a AIDS é caracterizada por um conjunto de ativistas cuja marca central de seus investimentos militantes é a soropositividade e a experiência da doença. Tal peculiaridade tem sido vista como um dos ingredientes principais do engajamento na luta contra a doença. Uma análise recente, sobre as etapas de construção da AIDS como um problema coletivo, destacou que o aparecimento das ONG/AIDS está associado, dentre outras coisas, a ativistas contaminados com o vírus (PETRARCA, 2015). Contudo, a AIDS não foi a primeira doença a mobilizar engajamentos a partir dos doentes, outras enfermidades do passado já demonstraram ser a experiência da doença um elemento constitutivo da mobilização, como, por exemplo, a associação de pessoas com diabetes, com câncer, dentre outras. 0 diferencial da AIDS com relação a outras doenças, segundo Bastos (2002), está na capacidade de intervenção e politização dos atingidos pela enfermidade. Assim, tal característica desse ativismo nos permitiu indagar quem são e a que espaços estão conectadas as principais lideranças do "ativismo de AIDS".

Nesta terceira modalidade de engajamento, a descoberta da doença transforma-se em uma experiência determinante que conduz a uma mudança de fase e a uma reorganização da vida. É dessa forma que a doença se torna um momento decisivo de ruptura biográfica, de reorientação da carreira, de transformação da vida que contribui para redirecionar todos os investimentos 
pessoais e profissionais. Essa ruptura contribui para gerar aquilo que Hughes chama de ponto de inflexão, ou seja, "períodos sombrios de desesperança seguidos de uma alegre renovação de vida e esperança" (HUGHES, E. 2005, p.164).

Tomaremos aqui o caso da história de vida de uma das militantes entrevistadas. Diferente da modalidade anterior estudada, este caso se caracteriza por um histórico social sem engajamento prévio e sem experiência de militância, seja ela política partidária, entidades de representação ou movimentos sociais. De forma semelhante ao que ocorre com muitas mulheres, essa ativista contraiu o vírus através do companheiro que a abandonou logo após o início doença.

Eu era viúva e sempre fui saudável. Conheci um homem que era soropositivo e ele não me falou da doença. Depois que adquiri o vírus, ele me abandonou. Sempre me cuidei tanto e, de repente, vi minha vida virar uma bagunça. Eu cheguei a ir para o fundo do poço, desabafa. (http://cadaminuto. com.br/noticia/123265/2011/06/06/aidscompleta30anoscom30milhoesdemortes Acesso em setembro de 2015)

Após descobrir sua condição sorológica, já em estágio de desenvolvimento avançado da doença, precisou se afastar do trabalho para realização do tratamento.

Fiquei internada no Hospital de Urgência durante oito meses. Fiquei muito debilitada, chegando a pesar 28 quilos. Mas minha filha, que na época tinha 12 anos, desenhava e sorria sempre. Isso me deu muita força. (http://cadaminuto.com.br/noticia/123265/2011/06/06/aidscompleta30anoscom30milhoesdemortes).

Nesse momento, em que a professora se encontrava em quadro de saúde bastante debilitado e necessitando de cuidados especiais, contou com a ajuda de amigos, como pode ser visto na seguinte fala: 
A minha comadre e a mãe dela são maravilhosas. Mãe Tereza dormia comigo, comprava meus alimentos, me dava banho, trocava minhas roupas e chegou até a doar sangue para mim. Elas ficavam comigo 24 horas. (http://cadaminuto.com.br/noticia/123265/2011/06/06/aidscompleta30anoscom30milhoesdemortes).

O uso do coquetel também necessitava de cuidados especiais, como a alimentação equilibrada, horário de sono regulado por dia e atividades.

Quem toma o remédio tem que ficar sob os cuidados dos familiares e dormir em cinco minutos, porque se tiver insônia com freqüência, a medicação pode causar distúrbios mentais. (http://cadaminuto.com.br/noticia/123265/2011/06/06/aidscompleta30anoscom30milhoesdemortes).

Contudo, mesmo com todos os cuidados, o uso dos remédios deixou sequelas no sistema nervoso central e, logo após a recuperação, ao tentar retornar ao trabalho, foi demitida não conseguindo mais lecionar. Essa experiência lhe permitiu perceber e sentir o preconceito que os portadores do HIV sofrem.

Quando eu fiquei doente, e precisei sair, a escola me deu o apoio como a qualquer outra pessoa que sai de licença médica, depois do tratamento, quando eu já estava bem e fui voltar, acabei sendo demitida. Eles não falaram que foi por causa da doença, eles não falam. Falaram que eu tinha ficado doente e era melhor não retornar. (Entrevista concedida em 2014).

0 preconceito sofrido pela professora começava a mudar sua vida, pois uma vez desempregada, não tinha como pagar o aluguel e foi preciso "morar em uma invasão". Esse foi um momento de grande dificuldade financeira sofrida, pois além de não ter condições para se manter, ainda cuidava dos filhos e precisava de uma atenção especial para que a doença não voltasse a se desenvolver novamente. 
Pode-se perceber que a descoberta e o desenvolvimento da doença contribuíram para mudar o seu lugar na sociedade, passando de uma professora saudável e plenamente capaz de manter a sua família, para uma mulher com uma saúde debilitada e que lutava pela sua vida. Tais condições a conduzia para o afastamento social gerado pelo preconceito com os soropositivos, como perda do seu emprego, depois sua casa e todas as dificuldades geradas por esta experiência. Contudo, essa mudança de condição pôde permitir uma reflexão sobre si e sobre o mundo, como explicita Hughes (2005) abaixo:

Às vezes a transição de um status para outro é considerada de tal importância que o candidato recebe instruções especiais sobre os cânones de conduta apropriados ao seu novo estado. Ele pode ser enviado numa jornada solitária em busca de uma visão, separado temporariamente das outras pessoas e das atividades normais, submetido a severas provações, obrigado a votos solenes. Ele pode ser obrigado a morrer simbolicamente como criança e renascer como homem. (HUGHES, E. 2005 p 165).

O período de descoberta da doença, o desemprego e a mudança na sua forma de vida, constituíram-se como um momento de transição, de ruptura ou, como define Hughes, (2005) um turn point. Esses momentos se tornam importantes, uma vez que permitem ao ator social uma reorientação biográfica, uma virada na vida, conduzindo a escolhas e permitindo uma reavaliação das aspirações. É por meio da ruptura com a situação de doente para a posição de ativista que essa militante consegue restabelecer o seu papel na sociedade ajudando outras mulheres a lutar contra o preconceito e dar um novo sentido à vida.

Esse processo tem início durante a realização do seu tratamento, pois foi durante uma das consultas regulares com o seu médico que o primeiro contato com o ativismo ocorre. Como o seu quadro de saúde havia se agravado rapidamente, uma equipe médica fazia o tratamento junto com o coordenador estadual 
de DST's/AIDS e para acompanhamento psicológico ela foi encaminhada para as redes de atendimento que funcionam como um suporte social para as vítimas. É por meio dessa rede que o primeiro contato com as lideranças do movimento acontece. 0 segundo contato se manifesta em uma das consultas médicas, a partir da qual ela teve acesso a um material de divulgação sobre um curso de capacitação feito para mulheres soropositivas com duração de dez dias em Natal, capital do Rio Grande do Norte. 0 evento, o qual contava com o financiamento do Ministério da Saúde para custear todas as despesas de quem tivesse interesse em participar, tinha como principal orientação conduzir essas mulheres a fundação da entidade POSITHIVAS em seus respectivos estados. Após decidir realizar o curso, retorna à Sergipe com as diretrizes para fundar a organização POSITHIVAS. Com o apoio da Secretaria Estadual de Saúde e do programa estadual DST/AIDs, convoca um conjunto de mulheres soropositivas e funda a entidade da qual se tornou coordenadora. Essa entidade, junto com a secretaria estadual, organizou o primeiro encontro nordeste de Cidadãs Posithivas, em Aracaju.

Podemos entender a realização desse curso como um dos importantes eventos que a conectam ao ativismo da AIDS e que a levam ao engajamento. Esse evento lhe permitiu a construção de laços, sobretudo institucionais e formais, uma vez que envolve entidades como o Ministério da Saúde e a Secretaria Estadual da Saúde, por meio do coordenador da política estadual. Tais laços foram posteriormente ampliados por meio da sua atuação na coordenação da ONG POSITHIVAS, pois esta atividade envolve um contato constante com lideranças e representantes das políticas de AIDS em diferentes âmbitos, municipais, estaduais e federais.

Essa ativista, que permaneceu por dez anos na entidade já mencionada, foi também representante estadual no Movimento Nacional de Cidadãs Posithivas e hoje é representante da Comissão de Articulação dos Movimentos Sociais. Sua intensa atuação lhe rendeu o título de cidadã Sergipana em 2011 e uma homenagem 
em uma publicação, realizada pela POSITIVHAS e que conta o cotidiano de mulheres infectadas pelo vírus da AIDS, denominada "Flores Vermelhas".

Como podemos perceber, sua militância no combate à AIDS muda o seu papel na sociedade, abandonando o lugar de mulher doente, para uma "cidadã" que luta pelos seus direitos e pelos direitos de outras mulheres soropositivas, ganhando notoriedade entre o movimento de luta contra a AIDS. É possível perceber que após a descoberta da doença, começa uma nova fase na vida. Por isso que o uso do termo "ponto de inflexão" serve para ilustrar essa mudança na trajetória da vida da professora, na qual ela vence o preconceito e torna-se referência na luta contra a doença no estado.

A conversão de vítima à ativista, como já salientamos, faz da AIDS uma das principais doenças a mobilizar os doentes. Tal característica se torna uma nova forma de recrutamento de militantes a partir, sobretudo, da sensibilização dos portadores do vírus. A experiência com a doença gera um conjunto de sentimentos (raiva, medo, angústia, exclusão, abandono) que pode contribuir para a adesão à causa. É nessa direção que alguns autores têm destacado a emoção como um dos principais ingredientes do ativismo (TRAÏNI, 2009; RECAPPÉ, 2008). E, em especial, no caso da AIDS, que desde sua emergência mobilizou a comunidade gay e lésbica a direcionar os sentimentos de indignação, opressão e segregação sofridos contra governos, cientistas, mídia e a sociedade como um todo (BROQUA \& FILLIEULE, 2009).

Todavia, a contaminação e a descoberta da doença, apesar de eventos importantes, só fazem sentido para o engajamento quando associadas ao conjunto de laços, contatos, vínculos com pessoas ligadas à causa. É por meio de uma extensa rede de sociabilidades que essas sensibilizações conduzem efetivamente ao investimento militante. 


\section{Considerações Finais}

O desafio principal deste texto consistiu, de um lado, em demonstrar as condições objetivas que conduzem ao engajamento. Centramos, para tal, no exame das redes de relações que podem se converter em recursos militantes. Nesse sentido, pode-se observar as redes de relações profissionais, as redes de base múltipla e aquelas decorrentes da experiência com a doença, como as que mais se destacaram no acesso à causa. Como espaços privilegiados de comunicação e informação, as redes aumentam as chances de acesso a determinados universos e pessoas, transformando-se em uma forma específica de recursos. De outro lado, o desafio se concentrou em destacar que as reconversões ideológicas são tão importantes quanto as demais, se constituindo como sustentáculo da ação militante. Esse duplo desafio permite compreender que as redes não se resumem a um extenso caderno de endereços, mas elas envolvem um comprometimento, um laço relativamente duradouro e uma forma particular de vínculo social que requer certa continuidade e que conduz a uma reorientação nas formas de perceber a si mesmo e aos outros.

Assim, para dar conta desses dois elementos centrais na construção do problema de pesquisa, a análise das carreiras se tornou fundamental, uma vez que por meio dela foi possível compreender como alguém se torna um ativista levando em consideração a forma como os contextos contribuem para criar tanto as condições da ação militante quanto as mudanças nas concepções de si e nas maneiras de ver o mundo. Portanto, ela permite apreender os itinerários a partir de uma lógica situacional e processual. É desse modo que as redes se tornam dispositivos analíticos e metodológicos interessantes, pois são observadas no exame das carreiras, estando atreladas às situações e aos eventos e ligando o ator ao universo de defesa de causas e aos "engajamentos de si".

Outros trabalhos têm apostado nessa mesma problemática, apontando a pertinência do conceito de carreira para apreender 
as dinâmicas das interações e dos espaços de sociabilidade que conduzem a formação de redes, as quais se tornam fundamentais para compreender o engajamento (OLIVEIRA, 2010). As redes de relações não só conectam o ator às causas como também contribuem para dar um sentido à ação militante. Esse sentido, muitas vezes, extrapola a esfera do engajamento e atinge outras esferas sociais, como profissional, familiar, pessoal, contribuindo para promover uma mudança nos rumos profissionais, nas relações de amizade, como observado nos casos estudados.

Um conjunto diversificado de estudos, desde os mais clássicos aos mais contemporâneos, já apontou a importância que exerce o conhecido, o amigo, o parente, no acesso a diferentes mundos sociais, desde a política até o mundo do trabalho e como as carreiras individuais se movem através das redes de sociabilidade (LEEDS, 1964; LEWIN, 1993; BEZERRA, 2013; OLIVEIRA, 2008; OLIVEIRA, 2010b). Para o caso específico dos estudos sobre engajamento, uma literatura recente (PASSY, 1998; 2002; PASSY \& GIUNI, 2001; McDAM \& PAULSEN, 1993) tem demonstrado como os laços de sociabilidade e as redes de relações contribuem para criar oportunidades de engajamento. Nesse sentido, o estudo das carreiras dos atores se torna um instrumento analítico interessante para compreender o peso que tais laços sociais têm nas diferentes esferas de vida (desde a pessoal ao espaço do trabalho).

\section{Ref erências Bibliográficas}

BASTOS, C. Ciência, poder, acção: as respostas à Sida. Lisboa: Imprensa de Ciências Sociais, 2002.

BECKER, H. Segredos e Truques da Pesquisa. RJ: Zahar, 2007. Outsiders. RJ: Zahar, 2008.

BEZERRA, M. O. Representantes políticos, relações pessoais e reputação. In: Seidl, Ernesto; Grill, Igor G. (Org.). As Ciências Sociais e os Espaços da Política no Brasil. 1ed. Rio de Janeiro: FGV, 2013, v. 1, pp. 279-318. 
BOURDIEU, P. As Regras da Arte. SP, Companhia das Letras, 1996.

BROQUA, C. \& FILLIEULE, O.. Act Up ou Les Raisons de la Colére. In: TRAÏNI, C. 2009. Émotions...Mobilisation! Paris: Sciences Po, Les Presses, pp. 141-168, 2009.

COLLOVALD, A. Pour une Sociologie des Carrières Morales. In: COLLOVALD, A. L'Humanitaire ou le Management des Dévouements. Presses Universitaires de Rennes, pp. 177-225, 2002.

CANEDO, L. Gestão Familiar da Escola e Aprendizagem das Habilidades para o Ofício da Política. In: ALMEIDA, A. M. \& NOGUEIRA, M. A. A Escolarização das Elites. Petrópolis: VOZES, 2003, pp. 76-100.

COSTA, S. L. M. Aids: a construção de uma síndrome. Trabalho apresentado no XXXVI Congresso Brasileiro de Ciências da Comunicação, realizado de 04 a 07/09 de 2013.

FACCHINI, R. Sopa de Letrinhas? - Movimento homossexual e produção de identidades coletivas nos anos 90. RJ: Garamond, 2005.

FIGARI, C. As Outras Cariocas: interpelações, experiências e identidades homoeróticas no Rio de Janeiro. Rio de Janeiro: IUPERJ, 2007.

FORNEL, M. \& QUÉRÉ, L. La Logique des Situations. Paris: Editions EHESS, 1999. HUGHES, E. Ciclos, pontos de inflexão e carreiras. In: Teoria e Pesquisa. p. 163-172. Vol.46. 2005. Tradução e notas de Celso Castro

GALVÃO, J. AIDS no Brasil. A agenda de construção de uma epidemia. RJ: Editora 34, ABIA, 2000.

GOFFMAN, E. Manicômios, Prisões e Conventos. SP, Editora Perspectiva, 1996.

LEEDS, A. Brazilian Careers and Social Structure: An Evolutionary Model and Case History. American Anthropologist, pp. 1321-1346, n. 66, 1964.

LEWIN, L. Política e Parentela na Paraíba. Um estudo de caso da oligarquia de base familiar. RJ, Record, 1993.

McDAM, D. \& PAULSEN, R. Specitying the relationship between social ties and activism. American Journal of Sociology, pp. 640-667, 1993.

MELO, M. R. 0 engajamento no combate à "homofobia" em Aracaju: trajetórias, redes sociais e expertização. In: IX REUNIÃO DE ANTROPOLOGIA DO MERCOSUL. Anais... Curitiba, 2011.

OLIVEIRA, W. J. F. Representações Biográficas, Identidades Militantes e Atuação Profissional em ONGs. Composição: Revista de Ciências Sociais da Universidade Federal de Mato Grosso do Sul, v. 4, p. 79-94, 2010a. 
OLIVEIRA, W. F. O. Posição de classe, Redes Sociais e Carreiras Militantes no Estudo dos Movimentos Sociais. Revista Brasileira de Ciência Política (Impresso), v. 3, p. 49-77, 2010b.

OLIVEIRA, W. J. F. Gênese e Redefinições do Militantismo Ambientalista no Brasil. Dados (Rio de Janeiro. Impresso), v. 51, pp. 751-777, 2008.

PASSY, F. L'action altruiste. Geneve, Droz, 1998.

PASSY, F. Social Networks Matter. But How? IN: Mario Diani \& Doug McAdam, eds., Social Movement Analysis: The Network Perspective (Oxford University Press) 2002, pp. 1 a 42.

PASSY, F. \& GIUGNI, M. Social Networks and Individual Perceptions: explaining differential participation in social movements. Sociological Forum, vol. 16, n. 1, pp. 123-153, 2001.

PÉCHU, C. Les Générations Militantes à Droit au Logement. Revue Française de Science Politique, volume 51, n. 12, pp- 73-103, évrier-avril 2001.

PETRARCA, F. R. Ativismo Jurídico e Usos Militantes do Direito na Luta pela Igualdade Racial. Revista de Antropologia (USP. Impresso), v. 56, pp. 111145, 2013.

PETRARCA, F. R. A luta pelos direitos humanos: profissionalização de causas e politização do direito. Cadernos CRH (UFBA. Impresso), v. 27, pp. 181-199, 2014.

PETRARCA, F. R. A Luta contra a AIDS: uma causa, múltiplos saberes. REPOCS (Revista Pós Ciências Sociais), v. 12, n. 23, jan/jun, pp. 91-114, 2015.

RECAPPÈ, B. Raison, Emotion, Institution: comprendre les mobilisations estudiantes face a des regimes autoritaires: Hongrie 1956, Mexique 1968. These. Political science. Universite Montesquieu - Bordeaux IV; Institut d'etudes politiques de Bordeaux, 2008, f. 469.

RIBEIRO. M. R. Construindo uma causa: institucionalização e engajamento na luta contra a AIDS em Sergipe. Dissertação de Mestrado. Programa de Pós Graduação em Sociologia da Universidade Federal de Sergipe. 2014, f. 99.

SAWICKI, F. \& SIMÉANT, J. Inventário da sociologia do engajamento militante: Nota crítica sobre algumas tendências recentes dos trabalhos franceses. Sociologias, v. 13, n. 28, pp. 200-255, 2011.

TRAÏNI, C. Émotions...Mobilisation! Paris: Sciences Po, Les Presses, 2009.

Recebido em 15/12/2015

Aprovado em 30/12/2015 
